\title{
Causes of Climate Change and Its Coping Up Strategies in Case of Gechi Woreda, Bunno Bedelle zone,South Western Ethiopia
}

\author{
Habib Bati Geda \\ Department of Ecotourism and Biodiversity conservations \\ Mettu University, P.O.Box ,318, Bedele,Ethiopia
}

\begin{abstract}
This research was conducted to assess Causes of climate change and its coping up strategies in case of gechi woreda, south western Oromia, Ethiopia. Climate change refers to long term fluctuations of temperature, precipitation, wind and other elements of Earth's climate system. It is a change of climate which is attributed directly or indirectly to human activity that alters the composition of the global and/or regional atmosphere. In order to achieve the objective of the study both primary and secondary data were used. The quantitative data was analyzed using frequency, percentage and mean while the qualitative data was used to triangulate and substantiate the study. To select the sample population, two different sample sizes were used with different sampling procedures stratified random sampling techniques was used to classify 2 kebeles of the woreda in 2 separate strata and simple random sampling technique was used to select kebeles that represent those strata. The result of the study indicated that Natural climate variability observed over comparable time periods in the types of changes of temperature and rainfall. It occurs because of internal variability within the climate system and external factors. The external causes may be natural or human induced activity. Human activities cause climate change mainly due to fossil fuel burning and removal of forests. To overcome this motivation of communities through distribution of technological energy (alternative energy) sources to reduce the human dependency on natural resources of the environment, early warning system, information management, community-based disaster preparedness, and humanitarian actions are going to be critically essential to substantiate enabling environment for climate change adaptation is an appropriate strategies to minimize the impacts of climate changes.
\end{abstract}

Keywords: Climate change, Climate change variability, Climate change drivers, Climate change mitigation, Ethiopia

DOI: $10.7176 / \mathrm{JRDM} / 66-01$

Publication date:June 30th 2020

\section{INTRODUCTION}

\subsection{Background of the study}

Climate change is predicted to have major adverse consequences for the world's ecosystems and societies. Although a global phenomenon, the severity of the adverse effects of climate change will differ significantly across regions, countries and socioeconomic groups. Poor countries will suffer more, with the poorest in the poor countries likely to suffer most. Africa is highly vulnerable to the potential impacts of climate change and Ethiopia is often cited as one of the most vulnerable and with the least capacity to respond and adapt (Thornton et al. 2006).

Ethiopia already suffers from historical climate variability and extreme climatic events (Mesfin 1984, Pankhurst 1985, McCann 1987, IIRR 2007). In particular, frequent droughts coupled with environmental degradation and decline in food production are common and still remain major challenges to Ethiopia (NMA, 2006, , Senbeta et al. 2002,). Droughts and floods are common phenomena in Ethiopia, occurring every 3 to 5 years (World Bank, 2006). In particular, there is increased incidence of meteorological drought episodes, famines and climate-sensitive human and crop diseases in the northern highland and southern lowland regions of Ethiopia (World Bank, 2009, Aklilu and Alebachew 2009, Oxfam International 2010, UN-ISDR 2010). In many areas of Ethiopia, the frequency of droughts and floods has increased over the years, resulting in loss of lives and livelihoods (NMA, 2007, Oxfam International 2010). Climate change is expected to exacerbate the problem of rainfall variability, and associated drought and flood disasters (NMA, 2006).

However, the spatial and temporal variability of precipitation is high, thus large-scale trends do not necessarily reflect local conditions. Projecting into the future, most global climate models indicate some increase in rainfall in both dry and wet seasons in Ethiopia (NMA, 2006). Ethiopia 's National Meteorological Agency (NMA) identifies drought and flood as the major hazards in the future as well, with potential negative impacts on plant diversity and food security (FDRE, 2011). The major predicted impacts of climate change on plant diversity include frequent droughts and dry spells, shortened growing season, and increased incidence of pests and diseases (NMA, 2007). Without effective adaptation, there is likely to be a decrease in the total area suitable for plant species richness in the country. A study based on the Ricardian method predicts that a unit increase in temperature could result in reduction of plant species diversity (Deressa, 2007). 


\subsection{Statement of the problem}

Understanding the nature of climate change impacts, key vulnerabilities and indigenous adaptive responses at local levels, and the national institutional responses are important for developing appropriate adaptation strategies at community and farm levels. Nevertheless, there is limited research evidence as to whether or not climate change is perceived as a major problem or even a reality by the Ethiopian communities, particularly by the poor and most vulnerable farmers in the rural areas. Similarly, awerness to climate variability and change and its impacts on plant species diversity are not well documented. Therefore, this study was initiated to fill such knowledge gaps about impacts of climate changes on plant species diversity.

\subsection{Objectives}

\subsubsection{General objective}

To assess causes of climate change and its coping up strategies in case of gechi woreda, south western Oromia, Ethiopia.

\subsubsection{Specific Objectives}

$\checkmark \quad$ To identify causes of climate change on plant diversity

$\checkmark$ To examine Local peoples 'perceptions and understanding of climate change;

$\checkmark$ To determine mitigation measures of climate change on plant diversity

\subsection{Significance of the Study}

The result of this study, provide baseline information for other researcher to undertake similar study elsewhere. The study provides the necessary solutions to problem of the study area. The study used as input for government body,policy makers,planners and other stackeholders to make interventions. The local communities identify and reduce the different human activities that affect the species richness of the study areas .

\subsection{Ethical Consideration}

All research studies present a number of ethical and moral dilemmas which must be identified and addressed prior to carrying out any research studies in order to protect all participants from potential harm. We tried to establish good relationship with all the interviewees by making himself clear where he comes from, why the study was conducted. We arranged the interview time without affecting consent of each informal and interview.

\section{MATERIALS AND METHODS}

\subsection{Description of study area}

Gechi woreda is located in Buno Bedele Zone of Oromia Region, south western Ethiopia. It located at longitude and latitude of $8^{\circ} 27^{\prime} \mathrm{N} 36^{\circ} 21^{\prime} \mathrm{E}$ and $8.450^{\circ} \mathrm{N} 36.350^{\circ} \mathrm{E}$ respectively at about $462 \mathrm{~km}$ road distance southwest of Addis Ababa. The area has an altitude between 1500-2100m above sea level and humid agro ecology,with area coverage of 48,632, Gechi is borderd on the south by Didesa, on the East by the Jimma,on the north by Bedele of Benishangul-Gumuz Region,on the northeast the Didessa River which separates it from the East Wollega Zone,on the southeast by Gechi(Fig 1). 


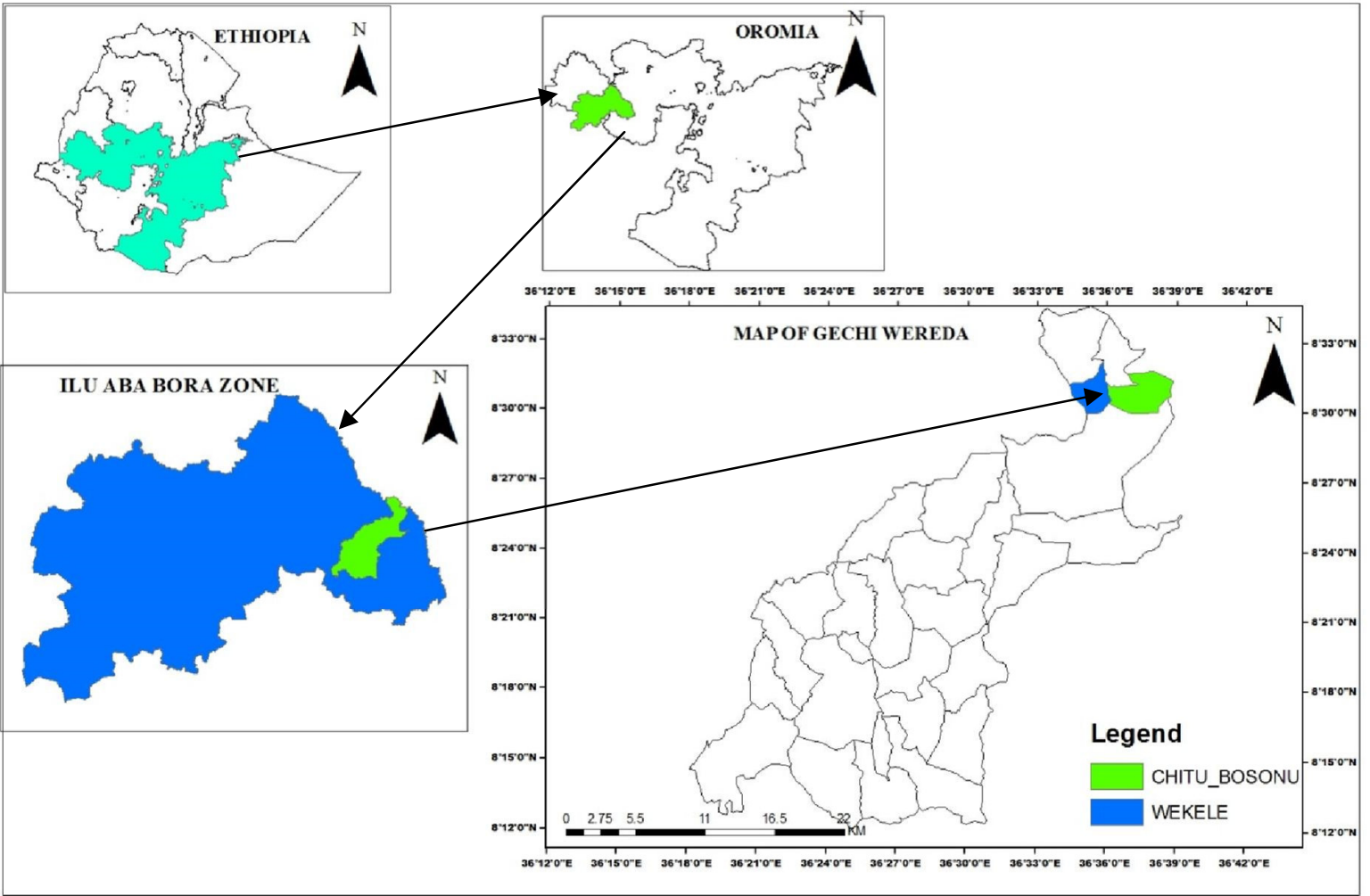

\subsubsection{Population}

Figure 1 : Map of the Study Area

A total population for Gechi Woreda is 70,478, of whom 35,307 were men and 35,171 were women. The majority of the inhabitants were muslim,with $87.7 \%$ while $10.58 \%$ of the populations were practiced Ethiopian Orthodox Christianity, and $1.66 \%$ were protestant (CSA,2007)

\subsubsection{Climatic Condition}

Gechi woredas receives an average annual rainfall ranging from $1825 \mathrm{~mm}$ and 1000 to $1200 \mathrm{~mm}$ and the minimum and maximum daily temperature of 13 and $18^{\circ} \mathrm{C}$ (LDMA, 2010; GDARDO, 2011).

\subsubsection{Soil type}

The soil of southwestern Ethiopia is in general classified as Nitosols according to the FAO/UNESCO or Alfisol according to the USDA soil classification systems. The major land use types are cultivated land/crop land,forest land and grazing land.

\subsubsection{Vegetation Cover}

Coffee is an important cash crop of this woreda, where over 50 square $\mathrm{km}$ are planted with this crop. Another important crop is tea;

\subsubsection{Socio-Economic Characteristics \\ Economic Condition}

There are diversified economic activities in this Woreda. Crop cultivation and animal rearing are the most known activities that the societies experience. Lowland areas of this Woreda are experienced by different types of cereal crops those mostly used for home consumption and cash crops those mainly used for commercial purpose. They all include sesame, maize, finger millet, cowpea, sorghum, groundnut, niger seed, sweet potato, cotton, sugarcane, mango, lemon, orange and papaya. But the amount of production of each item may vary based on the adaptation of weather system of the above agro-ecological zones.

Semi-lowlands are known by coffee, teff, maize, sorghum, barley, wheat, pearl, millet. Highlands are well known by different types of crops, vegetables and fruits like field pea, fenugreek, linseed, rapeseed, potato, tomato and avocado.

The dominant cash crops that are harvested by those settled people in the study areas include chat, ground nut and sesame and etc. After Oromo of Hararghe settled on Didessa valley that we termed as Chate resettlement site in Gechi Woreda, they adopt cattle breeding and bull fattening. Chate, the one which is the center of resettlement site, Aba Dula and Chara are considered as business centers in Gechi Woreda. The study areas are drained by Didessa River one of the tributary of Abay River (GWoLADO, 2018). 


\subsection{DESIGN OF THE STUDY}

Descriptive researches design was used for this study. This method is helpful to describe and obtain relevant and various forms of data concerning the existing status of the problems of the study area as well as incorporating human experiences from several dimensions. Descriptive research was used to describe answers to questions of who, what, where, when, how. It also enables to obtain the current information (Cochran,1963). Descriptive survey method focuses on investigating the current status, practice, the problem of institutional arrangement and capacity in assessment of climate change impacts on plant diversity.

\subsection{Data collection procedures}

Both primary and secondary data were used to accomplish this study with sufficient information. Data collection methods that were used described in subsequent section.

\subsubsection{Primary Data}

Primary data was collected using questionnaires and interview which are self-administered by the researcher to the local community of Gechi woreda

\section{a) Questionnaire survey}

The questionnaires have both open and closed ended questions. Open-ended questions solicited responses from the respondents on various issues under study. They also enabled defendants to give their varied views based on their experiences and thoughts. On the other hand, close-ended questions were used to solicit responses.

b) Interview

Face to face interviews were held with key respondents. Interviews was used because they involved direct contact between the interviewees and the interviewer and hence led to freedom and flexibility in terms of questions asked and answers given. Semi-Structured interviews enhanced flexibility in asking questions and changing the sequence of questions asked. Semi- structured interviews essentially used a set of predetermined questions which required highly standardized techniques of recording and facilitated in the generation of the required information by the interviewer. Semi-Structured interviews followed unrigged laid down procedure, asking questions in a form and order prescribed in the interview.

\subsubsection{Secondary data}

Secondary data collection involving gathering data from sources which have already been documented by other researchers. The study was employed by extensive library usage and internet search, collection of relevant materials from the press (documentaries and newspaper articles), books, journal papers and other published and unpublished works.

\subsection{Sampling technique and sample size}

In this study, to select the sample population, two different sample sizes were used with different sampling procedures. The first sample size was designed for the collection of data from households on climate change impacts on plant diversity. For deciding sample size and selecting samples, two stages samples were used. In the first stage stratified random sampling techniques was used to classify 2 kebeles of the woreda in 2 separate strata; namely: -Chitu Bosonu and Wekele kebeles based on geographical location, population density and availability of different infrastructures. In the second stage; simple random sampling technique was used to select kebeles that represent those strata. Based on this, 2 kebeles were selected from each stratum. The selected number is thoughed to be adequate to provide sufficient information and also to minimize unnecessary repetition of information. In second stage, a total sample size of 1618 households from two kebeles in general were taken.

The sample for the study was taken from the inhabitants of Gechi woreda. The kebeles selected were Chitu Bosonu and Wekele kebeles.

In stratified sampling , the population of size $\mathrm{N}$ is divided in to non-overlapping and mutually exclusive $\mathrm{L}$ subpopulation(strata) of size $\mathrm{N} 1, \mathrm{~N} 2, \ldots ., \mathrm{NL}$ and a random sample of size $\mathrm{n}$ is drawn from each stratum $\mathrm{h} ; \mathrm{h}=1,2, \ldots, \mathrm{L}$. For this study the total households were grouped into two kebeles(strata), these were :

*Chitu Bosonu (N1)

*Wekele kebele households (N2)

The size of the sample is one of the most important decisions in the planning of the survey. Therefore, to determine the sample size variability, confidence level and margin of error were considered. The sample size was determined by using the following formula (Cochran, 1977).

$$
n=\frac{\sum \frac{N_{h}{ }^{2} p(1-p)}{w i}}{\frac{N^{2} d^{2}}{Z^{2}}+N P(1-P)}
$$

Where

$\mathrm{n}=$ sample size needed for the study 
$\mathrm{N}=$ Total number of households in the selected kebeles

$\mathrm{Nn}=$ the number of households in each selected kebeles

$\mathrm{Z}=$ the critical values of standard normal cumulative distribution that corresponding to

$\alpha / 2$

$\mathrm{P}=$ Population Proportion

$\mathrm{d}=$ margin error

$\mathrm{WI}=$ estimated proportion of $\mathrm{Ni}$ to $\mathrm{N}$

$\mathrm{L}=$ Number of strata (kebeles).

The total sample size obtained for the study based on the given information as follow:

$\mathrm{N}=1618$ Total number of households in selected kebeles

$\mathrm{N} 1=850$ Total number of households in stratum 1

$\mathrm{N} 2=768$ Total number of households in stratum 2

$\alpha=5 \%$ level of significance

$\mathrm{Z} \alpha / 2=1.96$ (Tabulated value from normal distribution table at $\alpha=5 \%$ )

$\mathrm{P}=0.5$ there is no advance estimate of $\mathrm{P}$, so $\mathrm{p}=0.5$ is assume, which yields the maximum sample size.

$\mathrm{d}=0.05$ (by assuming)

$\mathrm{W}_{1}=\frac{N 1}{N}=\frac{850}{1618}=0.53 \quad \mathrm{~W}_{2}=\frac{N 2}{N}=\frac{768}{1618}=0.47$

$n=\frac{\sum \frac{N_{h}{ }^{2} p(1-p)}{w i}}{\frac{N^{2} d^{2}}{Z^{2}}+N P(1-P)}$

$\mathrm{n}=\frac{\frac{850^{2} x 0.5 x 0.5}{0.53}}{\frac{1618^{2} x 0.05^{2}}{1.96^{2}}+1618 \times 0.5 \times 0.5}+\frac{\frac{768^{2} x 0.5 x 0.5}{0.47}}{\frac{1618^{2} x 0.05^{2}}{1.96^{2}}+1618 \times 0.5 \times 0.5}$

$\mathrm{n}=161.6+148.8=310$

The sample allocations for each stratum (kebeles) were as follow:

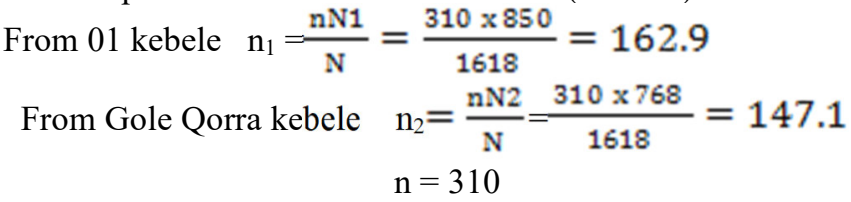

\subsection{Data analysis and presentation techniques}

Data collected through questionnaires and interview was coded and analyzed and the results was presented using tables, graphs, quantitative and qualitative statements and descriptions and descriptive statistics were used to determine frequencies and percentages. Further analysis of qualitative data generated from interviews was done using content analysis particularly on verbatim quotations or statements. The verbal information or statements madee by the researcher is coded and quantified to get uniform analysis of the data.

\section{RESULTS AND DISCUSIONS}

\subsection{Characteristics of Respondent}

Table1display that $147(47 \%)$ of the respondents are male whereas the outstanding $163(53 \%)$ of them are female. The respondents are also considered based on their work, 64(21\%) of them are students, $87(28 \%)$ of them are employed, 62(20\%) are merchants and 97(31\%) were farmer .Totally Individuals taken as sample are support us equally the goal to suggestion of the local community to understand their contribution to minimize impacts of climate change on plant diversity and also their expectation and perception towards biodiversity. 
Table1: Demographic Characteristics of sampled respondents

\begin{tabular}{lll}
\hline \hline Sex composition & Number of respondents & Percentage (\%) \\
\hline \hline Male & 147 & 47 \\
Female & 163 & 53 \\
Total & 310 & 100 \\
\hline \hline Occupation & Number of respondents & Percent (\%) \\
\hline \hline Student & 64 & 21 \\
Employed & 87 & 28 \\
Merchant & 62 & 20 \\
Crop Farmer & 97 & 31 \\
\hline \hline Total & 310 & 100 \\
\hline \hline
\end{tabular}

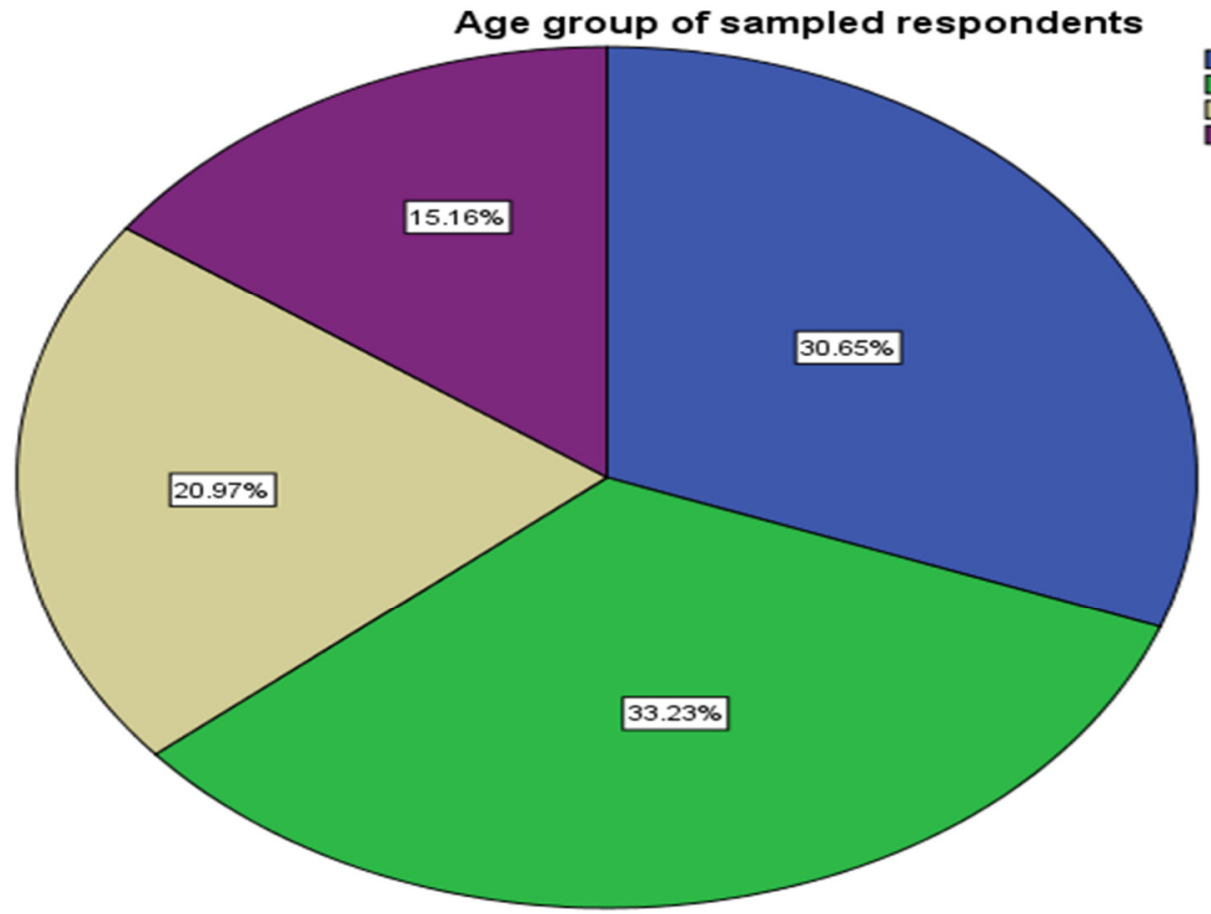

Figure2: Age groups of sampled respondents

As indicate in chart 1 above $95(30.65 \%)$ of the respondents are aged between (15-30), and the majority of sampled respondents $103(33.23 \%)$ aged between the age category of (31-45)and $65(20.97 \%)$ of them are aged between (46-60) and 47(15.16\%) are greater than sixty one ( $>61)$ years old. This indicated that majority of sampled respondents ranges in the age category of ample human power that have interested to participate in any ecotourism initiative.

\subsection{Source of income.}

In order to identify the major source of income, basic data were collected from the respondents. Based on their response crop farming, livestock rearing, mixed farming (both livestock rearing and crop farming) and other income generating activities like handcraft and beekeeping activities are the major source of their income. 


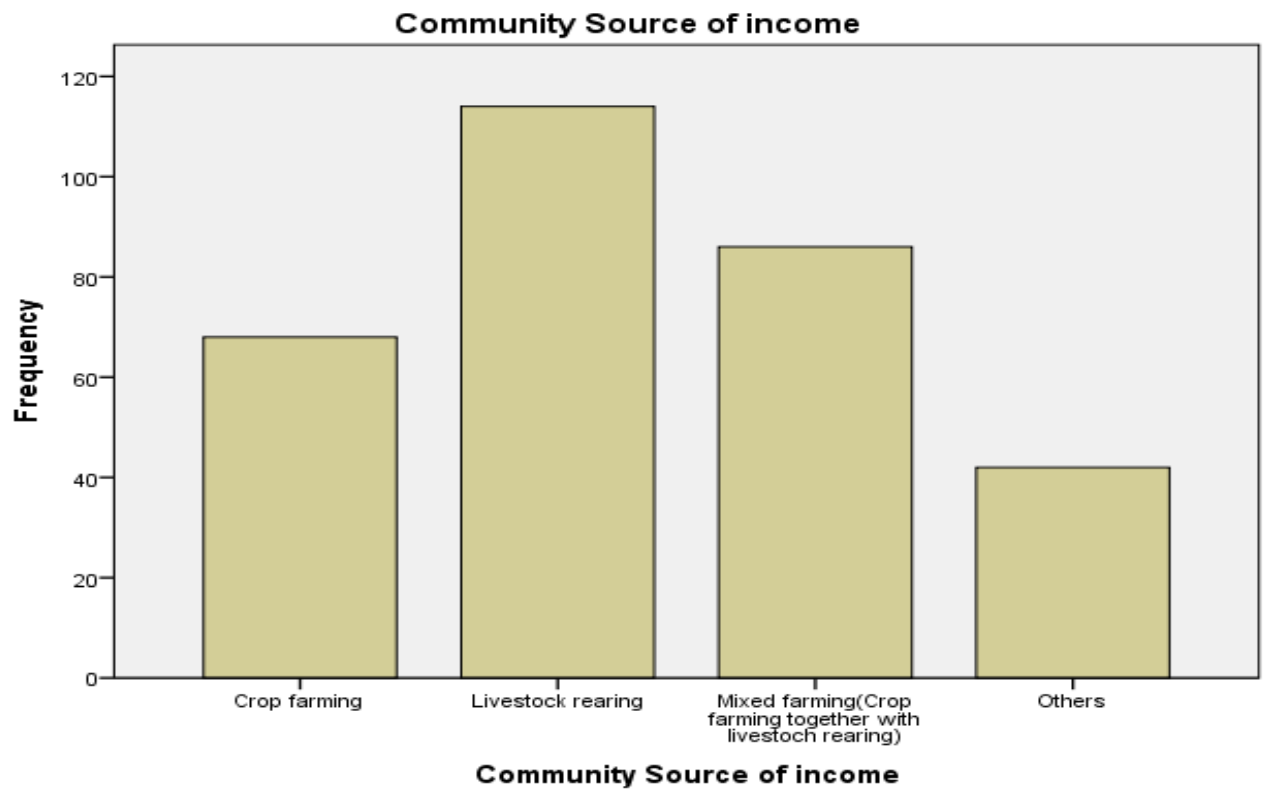

Figure 3: Community source of income

Concerning community source of income $86(27.7) \%$ of respondent mentioned that mixed farming (both crop farming and livestock rearing) is their income generating activity and crop farming accounts $68(21.9 \%)$ and the majority of them practice livestock rearing $114(36.8) \%$ and other income generating activities like handicrafts and bee keeping activities contributed 42(13.5). Human population increase, need of grazing land and agricultural expansion will negatively affect the potential resource of the areas unless other alternative income generating activity is established in the area, the potential resource of the area could be destructed as a result of Anthropogenic impacts wich leads to climate change impacts on crop variety.

\subsection{Key actors to minimize the impacts of climate changes.}

It is crucial to identify opinions of community towards the key role players for sustainable reductions of the causes that leads to climate change. The survey result of sampled respondents showed that majority of sampled respondents revealed that the collabrations of governmental organizations, Non-governmental organizations, community leader and local community play great role to overcome the cause and consequenses of climate change on plant diversity rather than working in separations(Figure 4:).

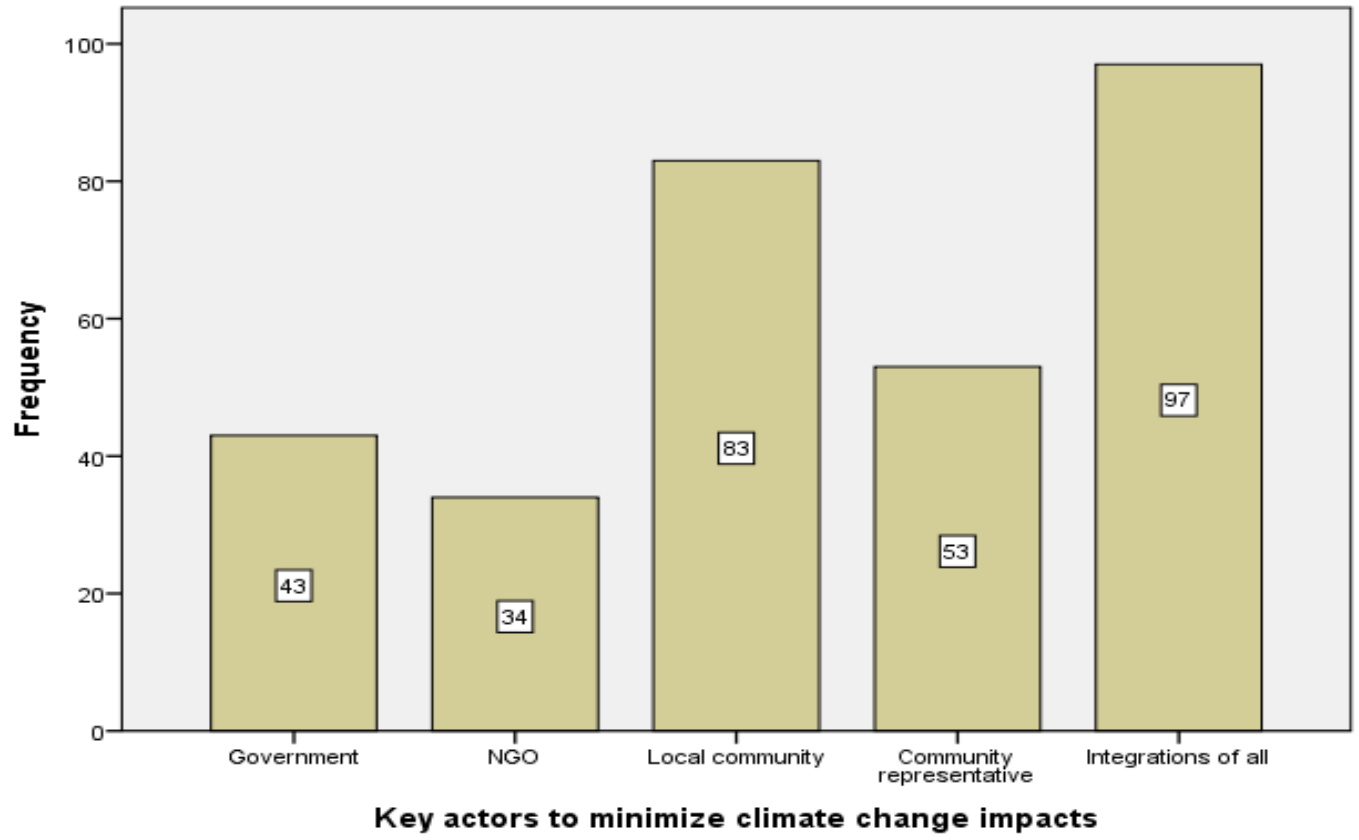

Figure4: Local people's opinions about who should play crucial role to minimize the impacts of climate change on plant diversity. 
Given that any project is not gained its ultimate success without involvements of community starting from its planning stage up to its implementations. It is crucial to identify opinions of community towards the key role players for sustainable reductions of the causes that leads to climate change. The survey result of the respondents showed that majority (30.9\%) of sampled respondents revealed that the integrations of governmental organizations, Non-governmental organizations, community leader and local community play great role to overcome the cause and consequenses of climate change on plant diversity rather than working alone. Mostly (26.8\%) of sampled respondents mentioned local community play crucial role for ultimate minimizations of factors that reduce plant diversity as a result of change in climate and (17.15\%) of sampled respondents revealed that community representatives play great role through initiating community to be organized and strive for potential resource protections. The result indicated that succeful minimizations of the change in climate due to human activities need cooperations and collabrations of different concerned stacheholders with the main focus of community as substantial control of the resource .This result is in agreement with the study conducted by (Admassie, 2008) on Stakeholder perception on climate change and adaptation strategies in Ethiopia.

\subsection{Causes of climate change}

The survey results of sampled respondents revealed that Deforestations, Agricultural expansions for the seek of expanding their farmland overgrazing by their cattle were the main factors that facilitates climate changes in an areas wich inturn leads to failures of plant diversity in an area that coping with changing climatic conditions. (Figure 5:).

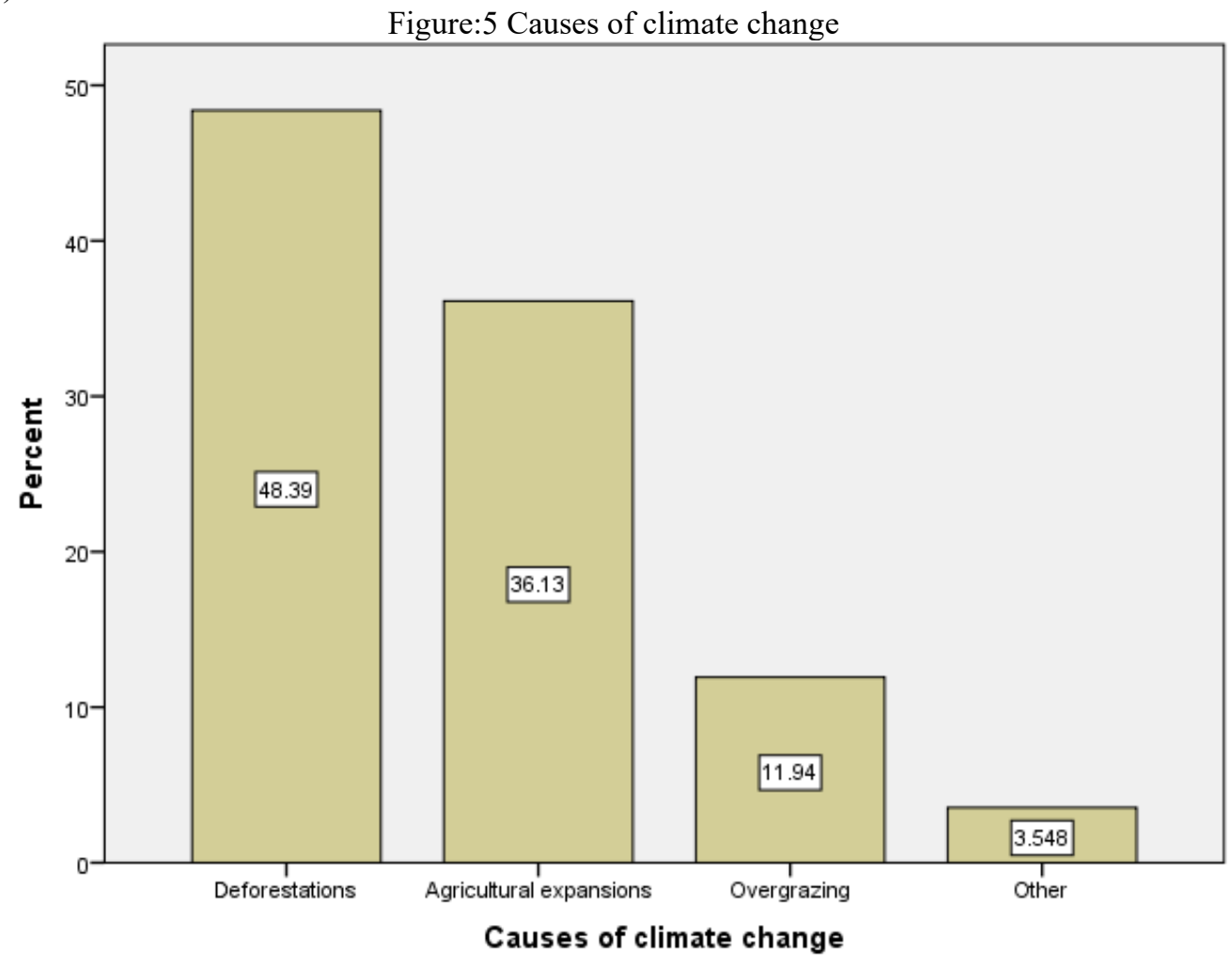

Regarding the factors that leads to climate change the respondents were asked. The majority of respondents $(48.39 \%)$ revealed that cutting of trees for different purposes were the major causes of that alters the climate conditions of the areas and leads to changes in plant variations that was grown from time to time in the areas.Mostly $(36.13 \%)$ of respondents mentioned that Agricultural expansions is one causes of climate change in the areas .They revealed that the areas had various plant diversity before ten years later. However now a days due to increaments in human populations the need of human is increase from time to time, to satisfy their needs community expands agricultural lands from time to time. This conversions of forest lands to agricultural lands was the main causes of climate changes in the areas,that leads to change in plant diversity to be grown in the areas. Some of the respondents(11.94) replied the areas are known by cattle productions . The overgrazing by this cattle was resulted in soil erosions by winds and runnof during wet seasons, this affected plant that was grown in the areas wich was reduce the variety and diversity of the plants that was grown in the areas.Minority of respondents mentioned that their was other factors that leads to climate changes like pollutions of the environments by different solid pollutants that was added to the environments and different chemicals from fertilizers were another factors that contributed for changing climate wich minimizes the types of plants grown. This result is inline with the study conducted by 
(Birhan ,2017) on Impacts of Climate Change on Crop Yields revealed that agricultural expansions was the main causes of climate changes that minimize crop yields in the study area.

\subsection{Temperature Distributions of Gechi Woredas}

Table 4: Average Temperature distribution in Gechi Woreda per month (2016-2017)

\begin{tabular}{|c|c|c|c|c|c|c|c|c|c|c|c|c|c|}
\hline Months & $\mathrm{J}$ & $\mathrm{F}$ & $\mathrm{M}$ & $\mathrm{A}$ & $\mathrm{M}$ & $\mathrm{J}$ & $\mathrm{J}$ & A & S & $\mathrm{O}$ & $\mathrm{N}$ & $\mathrm{D}$ & Total \\
\hline $\begin{array}{l}\text { Monthly Max } \\
\left({ }^{0} \mathrm{C}\right)\end{array}$ & $\frac{\text { ì }}{\text { aे. }}$ & $\hat{a}$ & तี & ָู & ָ̊ & $\hat{i}$ & ڤ̊̀े & $\frac{\tilde{b}}{\pi}$ & $\stackrel{n}{0}$ & ¿े & ָ̃ & $\begin{array}{l}0 \\
\text { nె } \\
\text { ָे }\end{array}$ & ॄே. \\
\hline $\begin{array}{l}\text { Monthly Min } \\
\left({ }^{0} \mathrm{C}\right)\end{array}$ & $\stackrel{0}{0}$ & $\stackrel{n}{n}$ & $\stackrel{m}{\varrho}$ & 三 & $\stackrel{\nabla}{=}$ & $\stackrel{\infty}{\circ}$ & $\stackrel{0}{m}$ & $\begin{array}{l}0 \\
0 \\
0\end{array}$ & $\stackrel{+}{\circ}$ & 官. & ڤे & $\stackrel{m}{m}$ & ป̊ \\
\hline A/Average $\left({ }^{0} \mathrm{C}\right)$ & $\stackrel{+}{i}$ & $\begin{array}{l}\infty \\
0 \\
i \\
\end{array}$ & ñ & $\begin{array}{l}6 \\
6 \\
6\end{array}$ & $\begin{array}{l}\mathscr{6} \\
\infty \\
0 \\
-\end{array}$ & in & $\begin{array}{l}\text { Jे } \\
\stackrel{n}{n}\end{array}$ & $\stackrel{ \pm}{\square}$ & $\begin{array}{l}\stackrel{n}{\ddagger} \\
\stackrel{n}{=}\end{array}$ & $\begin{array}{l}\infty \\
n \\
n\end{array}$ & ㅇ. & $\stackrel{+}{m}$ & $\stackrel{g}{\dot{I}}$ \\
\hline
\end{tabular}

\section{Source: - Gechi Woreda Meteorology Station, 2017}

The amount and distribution of temperature is based on the topographic variation and agroclimatic differences of the area those playing a major role to maximize and minimize its daily, monthly and annual. As table 4 above depicts, the total annual temperature of Gechi Woreda is about $194.94^{\circ} \mathrm{c}$ with maximum temperature $26.36^{\circ} \mathrm{c}$ in December and minimum temperature is about $9.96^{\circ} \mathrm{c}$ in November. Temperature increases from dega to woinadega then kola. The average temperature of this Woreda is about $18.25^{\circ} \mathrm{c}$. This indicated that the temperatures of the area is increasing from time to time wich leads to reductions in plant species diversity as aresults of climate change.

\subsection{Rainfall Distribution}

Table 5: Average Rainfall distribution in Gechi Woreda per month (2016-2017)

\begin{tabular}{|l|l|l|l|l|l|l|l|l|l|l|l|l|l|}
\hline Month & J & F & M & A & M & J & J & A & S & O & N & D & Total \\
\hline RF/mm & 0 & 0 & 19 & 100 & 419 & 429 & 203 & 211 & 170 & 115 & 0 & 5 & 1671 \\
\hline
\end{tabular}

Source: - Gechi Woreda Meteorology Station, 2017

Because of the variation in elevation, temperature, forest cover and others, the amount of rainfall is not the same in all parts of the globe. This is true in the case of the study areas. Total annual rainfall in Gechi Woreda is about $1671 \mathrm{~mm}$ and it decreases as one move from dega, woina-dega then kolla. The maximum rainfall is $429 \mathrm{~mm}$ in June and minimum is $5 \mathrm{~mm}$ in December while no or very minimum precipitation in November, January and February because those months are dry season even in many parts of the country.

The distribution of both temperature and rainfall is uneven because of manmade and natural factors globally and particularly in the study areas. Months from April to October are known as rainy seasons both in Woreda and the study areas but the total amount of rainfall can have some differences. This showed that the variations in both rainfall and temperatures in the study ares were the main causes for plant species variations from time to time.

\subsection{People's opinions on mitigation measures to climate change}

Survey results of the respondents showed that plantings of drought resistant crops,Diversifications of Agricultural crops,Creating awerness to the community concerning causes and consequenses of climate changes and use of alternative energy resource to reduce community dependence on natural resources were some of the the strategies to mitigates the impacts of climate changes on plant diversity(Figure 6). 


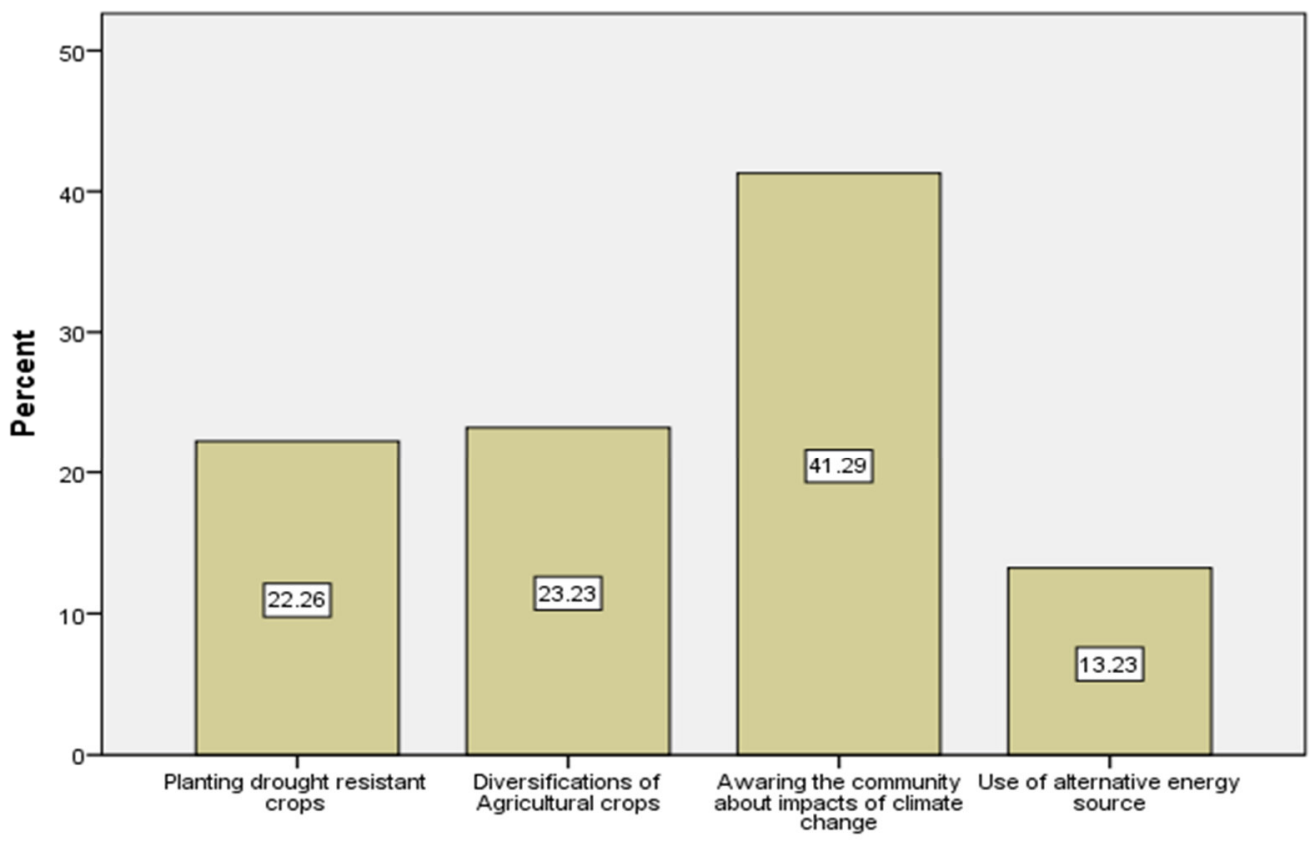

Peoples opinions on Mitigation measures to climate change

Figures6: People's opinions on mitigation measures to climate change

Given that community participation is a crucial element to mitigate and minimizes the impacts of climate changes on plant diversity, it is important to investigate the community's interest towards resources conservations and how to reduce the impacts of climate changes on crop diversity's results indicated in figure (6) showed that majority (41.29\%) of sampled respondents revealed that the impacts of climate changes on plant diversity should minimized through awering the community to reduce the facors that leads to changing climatic conditions like:Conversions of forest lands to more farmlands,Deforestation activities and burnings of fossil fuels. $23.23 \%$ of sampled respondents mentioned that intercropping's and diversifications of agricultural crops like early maturing and heat tolerant crop species and varieties were the main strategies to mitigate the impacts of climate changes. $22.26 \%$ of respondents mentioned that selection of the most suitable crops and cropping systems as per land capability class and rainwater availability (length of growing period), selecting early maturing and drought resistant crops; were an important solutions to overcome the impacts of climate changes on plant diversity. $13.23 \%$ of sampled respondents revealed that motivation of communities through distribution of technological energy (alternative energy) sources to reduce the human dependency on natural resources of the environment is an appropriate to minimize the impacts of climate changes. This indicated that climate change has an influence on forest through; Phenological change (cyclical events happening in plants, flowering, fruit production, maturity) shifts the geographic ranges of some tree species change in vegetation composition. leading to failure of reproduction \& forest products, due to death of their pollinators and seed dispersers. To overcome this drought resistant, early maturing and heat tolerant crop species and varieties have been developed. This results in line with the study conducted by (ACCCA, 2010). On Farm-Level Climate change Perception and Adaptation in Drought Prone Areas of Tigray, Northern Ethiopia.

\section{Conclusion and Recommendations}

Ethiopia has contributed very low to the current climate change. However, it has great impact in the country itself. Climate that was developed using historical data of temperature and precipitation from 1951 to 2005 for selected stations in Ethiopia showed the year-to-year variation of rainfall for the period. These changes in the physical environment are expected to have an adverse effect on agricultural production, environment, and plant diversity.Causes/drivers of climate change in the country are divided in to two as major and minor. Deforestation and forest degradation, land use change, and agriculture are considered as major drivers while transport, power, industry, and buildings are minor ones. Particulaery in the study area Climate change causes wide-ranging effects on the environment, and plant diversity and related sectors, including water resources, agriculture and food security, human health, terrestrial ecosystems and biodiversity as result of human population increament, to satisfy their own need their expand agricultural lands and overgrazing by their cattle were the main causes for change of climate which leads to change in plant diversity of the areas. To overcome this the following recommendations were forwarded.

$\checkmark$ Early warning system, information management, community-based disaster preparedness, and 
humanitarian actions are going to be critically essential to substantiate enabling environment for climate change adaptation.

$\checkmark \quad$ As future climatic conditions unfold and farmers learn how to implement adaptive strategies (which in turn will depend on the form of tenure, incomes, etc.), farmers could make long term adjustments such as changing crop varieties that are grown as well as where they are grown (i.e. location).

$\checkmark$ Traditional and contemporary coping mechanisms to climate variability and extreme should be strengthened.

$\checkmark \quad$ selection of the most suitable crops and cropping systems as per land capability class and rainwater availability (length of growing period), selecting early maturing and drought resistant crops should be needed.

\section{REFERENCES}

Abate Senbete (2009). Climate Change Impact on Livelihood, Vulnerability and Coping Mechanisms: A Case Study of West-Arsi Zone, Ethiopia. LUCSUS, Lund University SE- 22644, Lund, Sweden

ACCCA (2010). Farm-Level Climate change Perception and Adaptation in Drought Prone Areas of Tigray, Northern Ethiopia.

Admassie, A. (2008). Stakeholder perception on climate change and adaptation strategies in Ethiopia. Paper presented at the workshop on Climate change adaptation in Ethiopia, Nazareth, Ethiopia, 11-13

African Development Form (2010). Acting on Climate Change for Sustainable Development in Africa. Climate Change, Agriculture and Food Security. Addis Ababa. Issues Paper \#2.

Araujo, M.B., Diogo, A., Cabeza, M., Nogues-Bravo, D. and Thuiller, W., 2011.Climate changethreatensEuropeanconservationareas. EcologyLetters, 14: 484-492.

Ayana Salehu, Beyene Sebeko, Nebil Shekur, Sertse Sebuh and Tefera Tadesse (2011). Agriculture Sector Programme of Plan on Adaptation to Climate Change. Federal Democratic Republic of Ethiopia Ministry of Agriculture, Addis Ababa.

Bakkenes, M., Alkemade, J.R.M., Ihle, F., Leemans, R. and Latour, J.B., 2002. Assessing effects of forecasted climate change on the diversity and distribution of European higher plants for 2050. Global ChangeBiology, 8, 390-407.

Bazzaz, F.A., 1990. The Response of Natural Ecosystems to the Rising Global CO2 Levels. Annual Review of Ecologyand Systematics,Vol. 21, pp. 167-196

Birhan. G (2017). Impacts of Climate Change on Crop Yields in South Gonder Zone, Ethiopia

Brulle, R. J., Carmichael, J., \& Jenkins, J. C. (2012). Shifting public opinion on climate change: an empirical assessment of factors influencing concern over climate change in the US, 2002-2010. Climatic Change, 114(2), 169-188.

California Environmental Association, (2014). A review of agricultural emissions for the Climate and Land Use Alliance Technical annex to "Strategies for Mitigating Climate Change in Agriculture: Recommendations for Philanthropy."

Canadell, J.G., Kirschbaum MUF, Kurz WA et al (2007). Factoring out natural and indirect effects on terrestrial carbon sources and sinks. Environmental Science \& Policy 10(4):370-384

Capoor, K., Ambrosi, P, (2008). State and Trends of the Carbon Market 2008.Washington D.C. The World Bank.

Central Agricultural census Commission (CACC), (2002). Agricultural Sample Enumeration 2001/02, Part I, and Part II Addis Ababa, CASCC.

Central Statistical Agency (CSA), (2007). National Abstract Statistics. National Account 2007, Addis Ababa.

Desanker, P .V. 2002. Impacts of Climate Change on Life in Africa, WWF Climate Change Brief, WashingtonD.C.,USA.

FAO, (2005). Global Forest Resource Assessment 2005: progress towards sustainable forest management, Forestry Paper 147, Rome

Gechi Woreda Land and Agricultural Office, (2018)

Gechi Woreda Metrology Sub-Station (2017)

Grünzweig, J.M. and Körner, C., 2001. Biodiversity effects of elevated CO2 in species-rich model communitiesfrom the semi-arid Negev of Israel.OIKOS, 95: 112-124.

Hassen, A. and Virginia, D., 2001. Biodiversity in US forest under global climate change. Ecosystem,4: 161-163.

Kappelle, M., Van Vuuren, M.M.I. and Baas, P., 1999. Effects of climate change on biodiversity: a review and identification of key research issues. Biodiversity and Conservation, 8: 1383-1397. 8.

Körner, C., 2003. Ecological impacts of atmospheric CO2 enrichment on terrestrial ecosystems.

Magurran, A.E., 2004. Measuring Biological Diversity. Blackwell Publishing, Malden, MA. 256p.

Phil. Trans. R. Soc. Lond.A, 361, 2023-2041. 9. Mcclean C.J., Lovett J.C., Küper, W., Hannah L., Sommer J.H., Barthlott W., Termansen M., Smith G.F., Tokumine S. and Taplin J.R.D. 2005, African plant diversity and climate change.Annals of the MissouriBotanicalGarden, 92(2): 139-152. 
Thuiller, W., Lavorel, S., Araujo, M.B., Sykes, M.T. and Prentice, C.I., 2005. Climate change threats to plant diversity in Europe. National Academy of Sciences, Vol. 102, No. 23, 8245-8250.

URL 1. http://www.sanbi.org/ 13. Wilson, E.O. and Peter, F.M., 1988. Biodiversity. National Academy Press, Washington, D.C.,538 p. 